\title{
CULTIVATING RECALCITRANCE IN INFORMATION SYSTEMS RESEARCH
}

\author{
Carsten Sørensen \\ Edgar A. Whitley \\ Shirin Madon \\ Dasha Klyachko \\ Ian Hosein \\ Justine Johnstone \\ Department of Information Systems \\ London School of Economics and Political Science \\ Houghton Street \\ London WC2A $2 A E$ \\ United Kingdom
}

\begin{abstract}
There is an ongoing debate about how to improve the quality of empirical research efforts in information systems. One of the persistent issues within the debate concerns the relative importance of social and technical aspects of an information system and how to study these different elements. Contemporary research within science and technology studies suggests that social science inquiries can learn from empirical enquiries within the natural sciences through the notion of recalcitrance in experimental subjects. The aim of this article is to conduct an initial exploration of the usefulness of these ideas in the context of empirical information systems research. The following three research methods are subjected to a first theoretical analysis: (1) longitudinal, interpretive case study; (2) quantitative case study; and (3) laboratory experiments. For each of the three methods, an example is studied together with reflections from the researchers conducting the particular study. It is concluded that although this does not represent a solution to all methodological problems, adopting the perspective of cultivating recalcitrance and designing research methods to
\end{abstract}


include objectors provides an additional perspective, which can enrich and deepen the empirical work as well as further qualify the methodology discourse between researchers.

\section{INTRODUCTION}

Debates about the most appropriate ways to undertake research are features of healthy academic disciplines. Within information systems, there have been debates about the relative merits of positivistic and more interpretive research methods and the potential for their combination, for example (Lee 1991); about whether methodological diversity is beneficial for the field, for example (Benbasat and Weber 1996; Robey 1996); about the conflicting goals of rigor and relevance, for example (Benbasat and Zmud 1999) and commentaries; and about the possibilities of methodological pluralism(Allen and Ellis 1999; Jones 1999).

Alongside these debates, it has become increasingly common for researchers to spend some time stating their philosophical assumptions and explaining how they influenced the choice of research topic and approach (Eriksson et al. 2000; Walsham 1993). Recently there has also been a tendency for "confessional" papers that report in detail the features of the research process that had previously been left unsaid (Downey 1998; Schultze 2000; Scott 2000a; Sieber 2000; Whitley 1999).

In any discipline, there are many factors that can explain the diversity of perspectives on research approaches (Fuchs 1992); however, the very nature of the phenomena being studied in information systems adds further complications. Whereas psychologists focus their attention on humans and computer engineers work with electronic devices, information systems researchers study a phenomenon that is generally recognized as containing both human and technical elements. Although it can be argued that, in practice, all areas study such hybrid elements (Latour 1993), in practice most disciplines manage to "purify" their focus into technical or social objects.

For information systems, the inextricably intertwined nature of the systems being studied has been shown by a number of researchers. For example, Hanseth and Braa (1998) examine the introduction of a new enterprise resources planning system and highlight the way in which the new system takes on a life of its own and becomes a traitor to the original plans supporting its introduction. In this way, the technology is seen to have agency in much the same way as human elements of the organization. Mitev (2000) shows how a new computerized booking system for French railways changed both the work processes and organization into which it was introduced. The vast number of different 
accounting systems in a large multinational organization (Ciborra and Hanseth 1998) has a profound effect on the ability of the organization to implement a corporate infrastructure and causes us to re-evaluate our notion of an infrastructure as being something "out there" that sits beneath an organization providing useful services.

The convenient fiction of differentiating between "the system" and "its social context" can help with individual pieces of research (Henfridsson 1998). It does not, however, deal with the underlying division between the methods of the natural sciences that are most appropriate for understanding the system and the methods of the social sciences used for its social context. At first sight, it would seem that this is a division that cannot be overcome. Fortunately, recent thinking in science and technology studies offers a set of concepts that may help us improve our understanding of the two aspects. As information systems research constantly is confronted with complex technical and social phenomena, theories concerned with discussing and comparing natural and social sciences could intentionally enrich the discourse.

The concept of recalcitrance, as discussed within the context of comparing the social sciences with the natural sciences, is presented and discussed in this paper as a means of characterizing empirical information systems research efforts. This paper aims at initiating a debate of how the concept of recalcitrance can provide researchers with a better theoretical understanding of the phenomena they are studying and practical guidelines for improving the quality of information systems research as a whole. Recalcitrance may clarify our understanding of the inherent differences between studying human and non-human subjects, in a similar way as the application of different perspectives and approaches can highlight, qualify, and contextualize empirical findings (Trauth and Jessup 2000). Moreover, efforts to improve the recalcitrance of subjects can be applied to both the more technical and the more social elements of information systems with the possible consequences that the resulting research will reach a deeper understanding.

The paper, therefore, provides a theoretical reappraisal of research methods in information systems that draws upon the notion of recalcitrance. Section 2 reviews the work of science and technology studies and their application in the field of information systems. Section 3 introduces the concept of recalcitrance as it applies to social and technical objects of inquiry, arguing that researchers should try to cultivate the concept in their research design. Section 4 reviews a number of research approaches in information systems to demonstrate the conceptual clarifications obtained from the notion of recalcitrance of social objects in complex information systems phenomenon. Finally, section 5 offers some implications for research in terms of potential problems revealed by recalcitrance and steps which can be taken to cultivate recalcitrance in study design. 


\section{STUDYING THE NATURAL AND SOCIAL SCIENCES}

Science and technology studies look at the work of scientists and technologists and try to understand how they operate and achieve their goals (Biagioli 1999). The field encompasses a number of theoretical perspectives and has been used to study the work of scientists and engineers; for example, Latour and Woolgar (1986) reporting on the work of scientists at the Salk Institute; MacKenzie (1993) studying the engineers building nuclear warheads; and Callon (1998) studying the work of economists.

Some of the theoretical approaches developed by science and technology studies, such as the social construction of technology (Bijker et al. 1987) and actor-network theory (Law and Hassard 1998) have been used directly within information systems research (see Mitev [2000] for an example of the use of the social construction of technology; see Hanseth and Braa [1999], who use actornetwork theory to appreciate the problems of standardizing information systems in a large organization).

These studies of scientists, engineers, and markets have shown all the work that is involved in achieving results. Latour (1999, Chapter 2), for example, documents the vast numbers of layers of carefully designed and implemented mediation between the phenomenon under study and the scientific "result." The notion of the scientist "simply looking" for what nature can reveal has been shown to be a myth. High quality work in the natural sciences involves artificial situations, instruments, and mediation, with highly passionate scientists attempting to understand and explain what they are studying (Latour 2000).

When this is compared to the typical model of social science research, some differences can be observed. Although artificial laboratory experiments play a role in this research, often researchers try to study the phenomenon with as few artificialities as possible. Attempts are made to study the situation as it occurs, rather than in some controlled, artificial environment. Instead of the involved scientist, the social science model typically involves the researcher trying to maintain a distance from the phenomenon under study, so that the risk of affecting the results is minimized. Thus, most information systems studies are designed so that the researchers' biases and interests are kept out of the phenomenon being investigated, with action research being the obvious exception. One merit of this outside observer approach

is that the researcher is seen as not having a direct personal stake in various interpretations and outcomes, and thus personnel will often be relatively frank in expressing their views, provided a rapport of trust can be established (Walsham 1995, p. 77). 
Even if they choose not to act as outside observers, researchers often deliberate about feeding back initial findings from their studies to case study organizations for fear of the effect that any insights might have on the study (Scott 2000a), especially if the change being studied is still ongoing. The concept of recalcitrance as discussed by Latour (2000) and Stengers (1997) can help us initiate the discourse of this discrepancy between the involved, passionate scientist on the one hand and the detached, deliberately uninvolved information systems researcher on the other.

\section{RECALCITRANCE}

Recalcitrance, or the lack of susceptibility to control or authority, is introduced into the discussion of research methods by Bruno Latour (2000) who draws on the work of Isabelle Stengers (1997). Recalcitrance is an attribute of things being studied and refers to the extent to which they are uninterested in the "questions being asked of them." Recalcitrant objects provide answers on their own terms, rather than those of the authorities studying them; they can object.

Consider the case of atoms being studied by a physicist. These atoms are recalcitrant since they can produce results independent of the questions being asked of them by the scientists. The atoms are not constrained by the form of the questions; in an extreme instance, instead of undergoing the transformation the scientists expect, the atoms could blow up the laboratory.

Human beings, in contrast, generally do not have the same recalcitrance. Humans are interested in the questions that are asked of them and often respond to the process of questioning. Thus, there is always a risk with human subjects that they will give the answer they think the researcher wants to hear, rather than what they really believe. They might react to the questioner rather than the question and this risk is heightened by badly designed experiments

where scientists master all the inputs and outputs and leave the objects no other freedom than the ability to say "yea" or "nay"! It is a very poor science in which things have no more to say than the white and black pawns in a game of Master Mind and where the wild imagination of the scientist does all the rest of the talking (Stengers 1997, p. xvi).

Badly designed experiments in the natural sciences also run this risk, whereby the (unexpected) responses of the recalcitrant subjects are not picked up by the experimental design. Moreover, many instances of research on social things do not give "them a chance to redefine, on their own terms, what it is to be interrogated by science" (Stengers 1997, p. xv). 
We have now stipulated one characteristic difference between natural and social things. The recalcitrance of natural objects means that they will always respond to questions on their own terms. If the wrong questions are being asked, they have the ability to provide their own answers, for example by blowing up the laboratory. As a result, they are independent of the passion and involvement of the researcher asking the questions.

There are, therefore, three aspects of recalcitrance which can be used to raise questions about research design. These are shown in Table 1. First, there is the extent to which the subject of the study is inclined to be affected by the questioner. The second is the extent to which the study is designed to allow the subject to respond or rephrase the question on its own terms. Third is the extent to which the study is set up to record these rephrased answers.

Table 1. The Aspects of Recalcitrance and Their Effect on Research Design

\begin{tabular}{|l|l|l|l|}
\hline $\begin{array}{l}\text { Aspects of } \\
\text { recalcitrance }\end{array}$ & \multicolumn{2}{|l|}{$\begin{array}{l}\text { Phenomenon being } \\
\text { studied }\end{array}$} & Implications for research design \\
\hline $\begin{array}{l}\text { Affected by } \\
\text { questioner? }\end{array}$ & Natural & No & $\begin{array}{l}\text { No special allowances need to be made } \\
\text { for this }\end{array}$ \\
\cline { 2 - 4 } & Social & Potentially & Need to allow for this \\
\hline $\begin{array}{l}\text { Can answer in their } \\
\text { own way? }\end{array}$ & Natural & Yes & $\begin{array}{l}\text { No action necessary (although see third } \\
\text { aspect) }\end{array}$ \\
\cline { 2 - 5 } & Social & Yes & $\begin{array}{l}\text { But may need to be encouraged to do } \\
\text { so }\end{array}$ \\
\hline \multirow{2}{*}{$\begin{array}{l}\text { Can the alternative } \\
\text { answers be } \\
\text { observed? }\end{array}$} & Natural & $\begin{array}{l}\text { In some } \\
\text { cases }\end{array}$ & $\begin{array}{l}\text { Not a problem if the laboratory blows } \\
\text { up, may be missed in other cases }\end{array}$ \\
\cline { 2 - 5 } & Social & $\begin{array}{l}\text { In some } \\
\text { cases }\end{array}$ & $\begin{array}{l}\text { Some research designs do not make } \\
\text { this easy }\end{array}$ \\
\hline
\end{tabular}

The widely used notion of reflexivity in humans helps clarify what is meant by recalcitrance. Reflexivity, as used by authors such as Giddens (1984) and Beck (1992), refers to the feedback and feed-forward relationships within systems, notably to those relationships brought about by people being conscious, reflective, aware individuals. Walsham (1993) examines some of the methodological implications of reflexivity. As such, reflexivity bears a close relationship with the first element of recalcitrance. However, there is one important difference between the two concepts. While within the perspective presented here, a good empirical study could be facilitated by maximizing recalcitrance, the same is not always true of reflexivity. Some studies may require the subjects 
to be highly aware of their situation and reflexively considering it, whereas others may require them to not be consciously reflecting upon their situation. For example, we may wish to study them involved in their daily work, rather than when they are acting in a detached, reflexive manner (Introna 1997).

\section{CULTIVATING RECALCITRANCE TO IMPROVE THE QUALITY OF INFORMATION SYSTEMS RESEARCH}

The previous section has introduced the notion of recalcitrance and has argued that researchers could benefit from cultivating recalcitrance in empirical research studies. The hybrid nature of information systems phenomena implies a cultivation of recalcitrance in two different elements. First, there are the technical components of the computer system. To a large extent, the researcher here is in the same situation as the scientist studying atoms: the system does not respond to the interests of the researcher and is quite capable of acting in its own way. Researchers studying the technical component of the system must, therefore, ensure that their research design is capable of recording and analyzing the results that are produced, not just those that are expected. The recalcitrance of the social components, however, is more problematic. These run the risk of taking an interest in the work of the researcher and altering their responses accordingly. This problem can be exacerbated if the research approach does not allow them to respond in their own way, or if their responses are not recorded.

The remainder of this section reviews three research approaches, drawn from the taxonomy proposed by Galliers (1992), and highlights the three aspects of recalcitrance described above and suggests how it is possible to adapt those approaches to cultivate recalcitrance. As no previous work has been done appropriating the notions of recalcitrance to an IS discourse, we found it quite important in this initial effort to provide a discussion of several research approaches, as opposed to only discussing one. The role of the examples is merely to illustrate the points and to initiate debate within the IS community, not to provide any definite answers. We find that focusing on one approach exclusively potentially could steer the debate from the theoretical aspects toward more practical considerations and detailed deliberations concerning the particular, approach chosen. In particular we have deliberately postponed an analysis of the cultivation of recalcitrance in action research to a later paper since the complexity of this issue warrants a separate discussion. As argued by Mathiassen (2000), mixing traditional research methods with intervention can provide a good balance between concerns for rigor and relevance. Furthermore, Braa and Vidgen (2000) argue that the organization is the IS laboratory proper. 
Undertaking research is not the same as writing it up for publication and it is all too easy to highlight areas for improvement in examples of research if the published form of the research only provides limited details about how the research was actually undertaken. To that end, the choice of research approaches reviewed in this paper has been influenced by a further criteria: each example under review has been considered in conjunction with a research paper, written by the same authors, that reflects upon the research process undertaken. Thus, each research approach below draws upon an example of published research results and a reflection upon the research methods undertaken in that (style of) research.

Due to space constraints in this paper, we will only discuss three research approaches, drawing from the range of approaches found within information systems. Thus, some attempt to understand an information systems phenomenon in terms of an objective reality, which can often be subjected to numerical analysis, while others focus on the constructed, social nature of reality and discount the utility of reducing the phenomenon to numbers. The research approaches reviewed are longitudinal, interpretive case study; short term, quantitative case study; and laboratory experiment. The aim has been to initiate the debate of recalcitrance within information systems research by providing a first overview of the ideas and briefly discussing the implications by way of three examples. In subsequent research, we intend to cover the pertinent issues to a greater depth. As such, the analysis below only represents a first illustration of what such a discourse might entail.

\subsection{Longitudinal, Interpretive Case Study}

Longitudinal case studies form a major element of the interpretive tradition (Lee 1997), with researchers typically making multiple visits to a case study site over a period often of a number of years, and large numbers of interviews are undertaken with different members of the organization being studied. One variation of the case study, not discussed in this paper, is for the studies to be undertaken using ethnographically informed techniques.

The interviews are backed up by analysis of supporting documentation including planning documents, minutes of meetings, and internal memos. The debates about interpretive case study research as an appropriate method means that much has been written about the most effective way of undertaking such work. However, even in these cases, it is possible to make more useful contributions to the understanding of what is being done by cultivating the recalcitrance of the subjects. 
An example of a longitudinal case study is given by Scott and Walsham (1998) who studied the introduction and use of a new lending advisor system in a large British bank. Scott followed the system for three years, between 1993 and 1996, until the system had a "business as usual" status (Scott 2000b) and interviewed 140 people involved with the project. By interviewing local bank managers, board members, and key individuals in the software development team, she was able to appreciate the way that the new system enabled major changes in work and work life within the bank. She also reports on the implications that the bank's new credit rating system had on the shape of industry within the United Kingdom.

Much useful information was obtained from the interviews and it is important to undertake the interviews carefully. As Walsham (1995) explains,

[If] the interviewer directs the interview too closely, and refuses to allow interviewees to express their own views except in response to questions that are tightly controlled by the researcher, then the data obtained will lose much of the richness of interpretation which is the raw material of sensitive interpretive studies (Walsham 1995, p. 78).

In the language of this paper, an interview agenda which is too tightly controlled risks preventing the subjects from responding to questions in their own terms. This does not mean, however, that a totally passive strategy will be successful either, as the interviewees "may conclude that the researchers are either not interested in their views and/or that the researchers have no views of their own on the subject of investigation" (Walsham 1995, p. 78).

The first aspect of the notion of recalcitrance, namely the different ways in which humans and non-humans react to the questioner, is more concrete than the "principle of suspicion" proposed by Klein and Myers $(1999$, p. 83), which suggests not taking the views of informants at face value. Their justification for this approach draws on notions of socially created distortions and psychopathological delusions and other forms of false consciousness. While the principle is useful, viewing it in terms of recalcitrance makes it more generally applicable.

\subsection{Quantitative Case Studies}

Case studies have also been used within the positivisitic tradition of information systems research (Benbasat et al. 1987). Here, the case study is used as a site for observing a particular phenomenon which is studied by a variety of methods, including structured interviews and questionnaires. 
In their article in Communications of the ACM, Eriksson et al. (2000), provide an example of this as they reflect on the research approach followed for a study reported by El Sawy et al. (2000). A case study approach was used to study the communication patterns and potential for knowledge management in one part of a large high technology company based in California. The study, for reasons explained in the reflections paper, took place over a five day period and used a range of research approaches including structured interviews, surveys, and mathematical analysis of communication patterns.

The researchers explored issues of team dynamics, learning strategies, knowledge sharing, and business processes and discovered important differences in the kinds of interactions between program-oriented team members and systems-oriented team members. They also documented the role that face-to-face meetings had in the organization.

As part of the research process, the authors presented their results back to the organization. Interestingly, while there had been considerable participation in the data collection part of the study, when it came to the presentation of the results, the involvement was far lower. While this drop in interest could be explained in a variety of ways, an explanation drawing upon notions of recalcitrance could apply.

It is plausible that the workers in the organization were taking part in the study although they had no interest in the outcomes and could not see how the particular theoretical issues being studied would have an impact on their work. They would, therefore, be willing to participate in the data collection stage and offer responses to the questions asked of them. Given that the project had limited direct implications for them, there would be a natural tendency to give answers that seemed appropriate for the study.

This study shows that although the participants are able to answer questions in their own way, in practice it is often necessary to encourage them do so. The consequences of doing so would be very different. A research design that deliberately sought out objectors by challenging the responses given by the organization may have offered very different results. Moreover, raising objectors could have increased the interest of the organization in the study results and improved the likelihood of undertaking a follow-up study.

\subsection{Laboratory Experiments}

Much of the published research in information systems is based on some form of laboratory experiment. In some areas such as decision support systems and group decision support systems, this approach seems to dominate the field (Fjermestad and Hiltz 1996). These studies seek to study systematically the effects of certain key variables on various measures, normally through the care- 
ful design and implementation of controlled experiments where key variables are modified.

For example, in the area of group decision support systems, Fjermestad and Hiltz provide a summary of 122 empirical studies found in refereed journals and conferences between 1971 and 1996 that are based on controlled experiments. They define controlled experiments as situations where there were

two or more conditions deliberately created and contrasted, and other variables were controlled in some manner; and there was at least one independent and one dependent variable, which was measured and statistically analyzed (Fjermestad and Hiltz 1996, p. 347).

One feature of many of these studies is that they are typically based on relatively small problems, using ad hoc groups, and a high proportion of the studies use students as subjects. Fjermestad and Hiltz note that the duration of many of the experiments is typically quite short, with $62 \%$ of the experiments being completed in less than one hour.

The kinds of laboratory experiments undertaken by information systems research do not, therefore, rate particularly well in terms of recalcitrance. With artificially created groups of students solving simplified tasks, there is always the risk that part of the results being reported result from the experimental situation, rather than the task being studied (Introna and Whitley 2000). Since the subjects are so often students, there is also a risk that they will respond in ways in which they believe the teacher wants them to respond. Moreover, the limited duration of the studies minimizes the likelihood that they will become truly engrossed in the situation and act entirely naturally.

This is not to argue, however, that the notion of control and variation that underlies the experimental method has no value. Rather, recalcitrance warns about the potential problems with the kinds of studies favored by many researchers. Experimental situations with pre-existing groups working on real life situations (or certainly realistic problems) can be undertaken (Suchman 1987). An experiment trying to cultivate recalcitrance would be prepared for (and allow, if not encourage) participants to abandon the task if they felt it was not realistic.

Consideration of laboratory experiments also highlights the third aspect of recalcitrance, described above, namely the need to ensure that alternative answers are recorded. As Trauth and Jessup (2000) point out, the positivistic approaches used in many of these studies run the risk of ignoring valuable extra data from the study. These extra articulations can further develop our understanding of the phenomena under study. 


\section{DISCUSSION}

This paper has introduced the notion of recalcitrance and has argued that cultivating recalcitrance in the design and implementation of information systems research can be a valuable part of the methodology debate within our field. Table 2 summarizes the three research approaches considered in this paper, highlighting the potential problems that the concept of recalcitrance can reveal and the steps that can be taken to improve the research approach. In the case of the longitudinal case study, discussions of how to cultivate recalcitrance can in fact conceptualize and qualify Walsham's (1995) concern that the researcher must balance approach between controlling the interview and allowing the interviewees to control the research agenda. Acknowledging the importance of recalcitrance, furthermore, places Klein and Myer's (1999) concern expressed as the "principle of suspicion" within a constructive debate: if we are to investigate and interpret people, then we should carefully consider how to give them a voice. If we manage to do so, we can without moral or methodological dilemma study and question them. In the quantitative case study, the concern for recalcitrance relates to investigating the voice of the participants. As researchers applying a quantitative research method, we need to conceptualize the stated opinions and recorded actions. Cultivating recalcitrance in a quantitative case study can, for example, provide useful contextual information for the researchers on how interesting the participants find the study. In cases of disinterest, there is a risk of the responses being biased by lack of interest and involvement. In laboratory experiments, cultivating recalcitrance primarily concerns the artificiality of the setting. Due to the emphasis on control of the laboratory setting, there is a risk of the artificiality being at the center. Cultivating recalcitrance can be viewed as an ongoing process of negotiation between the researchers and subjects. Prior to the experiment, assessments and negotiations of how to increase the degree of realism in the experiment while maintaining the advantages of experiment could improve the quality of the research.

Table 2. Summary of How Recalcitrance Can Help the Research Methods Considered in the Paper

\begin{tabular}{|l|l|l|}
\hline Research approach & $\begin{array}{l}\text { Potential problems revealed by } \\
\text { recalcitrance }\end{array}$ & $\begin{array}{l}\text { Steps to cultivate } \\
\text { recalcitrance }\end{array}$ \\
\hline Longitudinal case study & $\begin{array}{l}\text { "Going native in interviews": } \\
\text { leading questions, disinterest }\end{array}$ & $\begin{array}{l}\text { Theoretically informed } \\
\text { "suspicion" }\end{array}$ \\
\hline Quantitative case study & Disinterest, low response rate & Confront objectors \\
\hline Laboratory experiment & Objector adaptation & Allow and encourage dissent \\
\hline
\end{tabular}


If, for example, an experiment aims at testing the usability of a certain systems feature, then the usability test should be based on a proper understanding of and involvement from the people with deep domain knowledge.

One of the implications of the principle described in this paper is that researchers should be seeking to increase the number of objectors to their research questions rather than to minimize them. At first sight, this appears to be counterintuitive and runs against the ideals of achieving widely applicable results. A useful comparison, however, can be made to the software testing process (Carstensen et al. 1995; Myers 1979). The purpose of software testing is to find errors with a good test being one which has a good likelihood of finding an error and a successful one being a test that finds errors. In the same way, from the perspective of recalcitrance, a good piece of research can be seen to be one that has a high likelihood of finding objectors and a successful one being one that does find objectors, although the absence of objectors also can reflect inadequate methods (Collins and Pinch 1998, Chapter 5). Similarly, the academic peer-review process provides an inter-subjective quality assurance system (Bergquist et al. 2001) where the quality of the products can be judged by the strength and recalcitrance of objectors. A MIS Quarterly reviewer will, for example, be expected to be more recalcitrant to the ideas in a paper submitted for publication than one submitted for a doctoral seminar.

Clearly, criticism can always be raised within a certain paradigm that any suggestion for significant rethinking ought to be reformulated in terms of general improvement of the methods applied. The suggestion to apply the concept of recalcitrance as a means of improving survey design could, for example, within the quantitative paradigm, be argued as the need for a more carefully designed survey instrument. Furthermore, adopting ideas from contemporary science and technology studies does not in and of itself represent a packaged solution to the problems associated with conducting high-quality empirical research within information systems. However, we would argue that the research design process as well as the general method debate within information systems research could benefit from the ideas discussed in this paper, in the sense that they bring with them a shift in perspective.

Social science researchers, argue Stengers (1997) and Latour (2000), should allow the people they study the right to object, similar to the right to object that natural scientist are forced to allow their objects of study. The perspective of cultivating recalcitrance and designing research methods to include objectors can potentially enrich and deepen the empirical work as well as further qualify the methodology discourse between researchers. As with any set of ideas brought from one area of concern to another, there is the need for appropriation and redefinition. In terms of the benefit of the ideas discussed in this paper; for positivist research approaches, the key is to give the people being studied a 
voice, and exactly how this could be implemented within a positivist paradigm needs to be analyzed further. In fact, it could be argued that a positivist approach already is an attempt to bring the concerns from natural sciences into the social sciences. The research paradigm will perhaps not easily acknowledge the need to give people studied a voice; the natural scientists does not have this concern (Pouloudi and Whitley 2000). There may be gains for positivist research in terms of cultivating recalcitrance in the early stages of the research process, for example, by more actively seeking objections to the context of the research questions being asked. In quantitative surveys, the process of operationalizing variables in order to get from the theoretical model to actual questions could be one area of concern.

In many respects, the organization can be viewed as the information systems laboratory (Braa and Vidgen 2000), and action research would appear, at first sight, to be a research method that is naturally inclined to reveal the recalcitrance of its subjects. Given the space limitations, and the three conflicting concerns of understanding, prediction, and change (Braa and Vidgen 2000), we have chosen to analyze this approach in greater detail in a future paper. Mathiassen (2000) suggests a multiple research method approach as a way of managing the balance between rigor and relevance in action research, thus potentially further widening the scope and complexity when analyzing recalcitrance in action research. As a small illustration of the complexity, the action researcher who attempts to introduce a change that does not fit with the organization is likely to meet objections. However, action researchers who attempt to combine the goals of academic rigor with changes to the organizational setting need to be careful that their involvement in the situation, which enables the change to take place, does not prevent the organization from having the opportunity to object to the theoretical insights being proposed. It would be all too possible for the organization to appreciate the changes that are being instigated and, therefore, to accept whatever contribution the researcher is claiming for understanding the situation.

The ideas discussed in this paper are primarily formulated from an analytical perspective. Science and technology studies are concerned with providing principled and detailed understanding the phenomena. Within information systems research, there is a strong tradition for also being concerned with sociotechnical change. Information systems research will work with computer science and human-computer interaction to suggest new technologies and patterns of work (Dahlbom 1996). Information systems research is also concerned with organizational change and strategic development (Ciborra and Associates 2000). These different concerns are expressed in empirical efforts ranging from very detailed ethnographic studies of work activities (Heath et al. 2000) and the design of support technologies to more principled investigations of the role of 
technologies in society. It has been argued that adopting multiple methods in empirical research efforts can fundamentally increase the quality of results (Sawyer 2000). If this is the case, then considerations as to how multiple methods can support the cultivation of recalcitrance and the design of objectors will be equally relevant.

\section{CONCLUSION}

The interdisciplinary character of information systems research has over the years resulted in cross-fertilization from the social sciences to information systems research, as documented by Jones (2000), for example. We have, in this paper, related current ideas from within the science and technology studies, a field that seems to receive increasing interest within the information systems research community (Jones 2000). Stengers (1997) and Latour (2000) suggest the concept of recalcitrance as a means for characterizing one of the differences between social and natural sciences. In this paper, we have examined these ideas in the context of information systems research methods by taking a closer look at three methods: (1) longitudinal, interpretive case study; (2) quantitative case study; and (3) laboratory experiments. For each method, we analyzed a particular study and, in order to cultivate the recalcitrance of the discourse, we also included methodological reflections made by the researchers themselves. In taking this initial step, we hope to stimulate a debate within information systems research exploring these novel approaches to understanding methodological choices and their consequences for our understanding of socio-technical contexts. If anything, our discipline is one of the middle ground, and as such we cannot easily define a strong and clear position (Sørensen 1999). Obviously, this paper only represents a first theoretical exploration. Subsequently, it is crucial to translate the theoretical considerations into practical concerns when conducting empirical studies. Much further analysis can be conducted within each of the types of empirical research efforts applied within information systems research. In particular, we will explore, in a future study, how to cultivate recalcitrance within action research, since this approach seems to exhibit very interesting characteristics. In action research, there is both the opportunity to engage in a rich debate between all involved parties, as well as the potential danger of, for example, the researcher acting as a glorified consultant. It could be argued that if the organization is the laboratory of information systems research, then it can indeed explode, but only if we as researchers allow it. 


\section{ACKNOWLEDGMENTS}

The authors are grateful to Tony Cornford and Ph.D. students in the Information Systems Department who read earlier drafts and whose questions helped refine the concepts discussed in the paper.

\section{REFERENCES}

Allen, D., and Ellis, D. “The Paradigm Debate in Information Systems Research," paper delivered at the Fourth UK Academy for Information Systems Annual Conference, York, UK, April 79, 1999.

Beck, U. Risk Society: Towards a New Modernity, London: Sage, 1992.

Benbasat, I., Goldstein, D., and Mead, M. "The Case Research Strategy in Studies of Information Systems," MIS Quarterly (11:3), 1987, pp. 369-386.

Benbasat, I., and Weber, R. "Research Commentary: Rethinking 'Diversity' in Information Systems Research," Information Systems Research (7:4), 1996, pp. 389-399.

Benbasat, I., and Zmud, R. W. "Empirical Research in Information Systems: The Practice of Relevance (with Commentaries by Lynda M Applegate and John L King, Thomas H Davenport and M Lynne Markus, Kalle Lyytinen and Allen S Lee)," MIS Quarterly (23:1), 1999, pp. 3-34.

Bergquist, M., Snis, U., and Ljungberg, J. "Practising Peer Review in Organizations: A Qualifier for Knowledge Dissemination and Legitimation." Journal of Information Technology (16), 2001 (forthcoming).

Biagioli, M. (ed.). The Science Studies Reader, London: Routledge, 1999.

Bijker, W. E., Hughes, T. P., and Pinch, T. (eds.). The Social Construction of Technological Systems: New Directions in the Sociology and History of Technology, Cambridge, MA: The MIT Press, 1987.

Braa, K., and Vidgen, R. "Research: From Observation to Intervention," in Planet Internet, K. Braa, C. Sorensen, and B. Dahlbom (eds.), Lund, Sweden: Studentlitteratur, 2000, pp. 251276.

Callon, M. (ed.). The Laws of the Markets, Oxford: Blackwell, 1998.

Carstensen, P., Sørensen, C., and Tuikka, T. "Let's Talk About Bugs!” Scandinavian Journal of Information Systems (7:1), 1995, pp. 33-54.

Ciborra, C. U., and Associates. From Control to Drift, Oxford: Oxford University Press, 2000.

Ciborra, C., and Hanseth, O. "From Tool to Gestell. Agendas for Managing the Information Infrastructure," Information Technology and People (11:4), 1998, pp. 305-327.

Collins, H., and Pinch, T. The Golem: What You Should Know About Science ( $2^{\text {nd }}$ edition), Cambridge, UK: Canto, 1998.

Dahlbom, B. "The New Informatics," Scandinavian Journal of Information Systems (8:2), 1996, pp. 29-47.

Downey, G. L. The Machine in Me, New York: Routledge, 1998.

El Sawy, O., Eriksson, I., Raven, A., and Carlsson, S. "Understanding Shared Knowledge Creation Spaces Around Business Processes: Precursors to Process Innovation Implementation," International Journal of Technology Management, 2000.

Eriksson, I. V., Dickson, G. W., and El Sawy, O. A. "Reflections on Designing Field Research for Emerging IS Topics: The Case of Knowledge Management," Communications of the AIS (3:6), 2000. 
Fjermestad, J., and Hiltz, S. R. "An Assessment of GDSS Methodology" in Proceedings of the Second Americas Conference on Information Systems, M. Goul and H. Owens (eds.), Phoenix, Arizona, August 16-18, 1996.

Fuchs, S. The Professional Quest for Truth: A Social Theory of Science and Knowledge, Albany: State University of New York Press, 1992.

Galliers, R. D. "Choosing Information Systems Research Approaches," in Information Systems Research: Issues, Methods and Practical Guidelines, R. D. Galliers (ed.), Oxford: Blackwell, 1992.

Giddens, A. The Constitution of Society, Cambridge, UK: Polity Press, 1984.

Hanseth, O., and Braa, K. "Technology as Traitor: Emergent SAP Infrastructure in a Global Organization," in Proceedings of the Nineteenth International Conference on Information Systems, R. Hirschheim, M. Newman, and J. I. DeGross (eds.), Helsinki, Finland, 1998, pp. 188-196.

Hanseth, O., and Braa, K. "Hunting for the Treasure at the End of the Rainbow: Standardizing Corporate IT Infrastructure," in New Information Technologies in Organizational Processes, O. Ngwenyama, L. D. Introna, M. D. Myers, and J. I. DeGross (eds.), Boston: Kluwer Academic Publishers, 1999, pp. 121-140.

Heath, C., Knoblauch, H., and Luff, P. "Technology and Social Interaction: The Emergence of 'Workplace Studies'," British Journal of Sociology (51:2), 2000, pp. 299-320.

Henfridsson, O. "Beyond the Container-View of Context," in Proceedings of the Sixth European Conference on Information Systems, W. Baets (ed.), Aix-en-Provence, France, June 4-6, 1998, pp. 673-683.

Introna, L. D. Management, Information and Power: A Narrative of the Involved Manager, Basingstoke, UK: Macmillan, 1997.

Introna, L. D., and Whitley, E. A. "About Experiments and Style: A Critique of Laboratory Research in Information Systems," Information Technology and People (13:3), 2000, pp. 161-173.

Jones, M. "Mission Impossible? Pluralism and Multiparadigm IS Research," paper delivered at the Fourth UK Academy for Information Systems Annual Conference, York, UK, April 7-9, 1999.

Jones, M. "The Moving Finger: The Use of Social Theory in WG 8.2 Conference Papers, 19751999," in Organizational and Social Perspectives on Information Technology, R. Baskerville, J. Stage, and J. I. DeGross (eds.), Boston: Kluwer Academic Publishers, 2000, pp. 15-32.

Klein, H. K., and Myers, M. "A Set of Principles for Conducting and Evaluating Interpretive Field Studies in Information Systems," MIS Quarterly (23:1), 1999, pp. 67-93.

Latour, B. Pandora's Hope: Essays on the Reality of Science Studies, Cambridge, MA: Harvard University Press, 1999.

Latour, B. We Have Never Been Modern (translated by Catherine Porter), New York: Harvester, 1993.

Latour, B. "When Things Strike Back: A Possible Contribution of Science Studies to the Social Sciences," British Journal of Sociology (51:1), 2000, pp. 107-124.

Latour, B., and Woolgar, S. Laboratory Life: The Construction of Scientific Facts (Revised Edition with a new postscript and index by the authors), Princeton: Princeton University Press, 1986.

Law, J., and Hassard, J. (eds.). Actor Network and After, Oxford: Blackwell, 1998.

Lee, A. S. "Electronic Mail as a Medium for Rich Communication: An Empirical Investigation Using Hermeneutic Interpretation," MIS Quarterly (18:2), 1997, pp. 143-157.

Lee, A. S. "Integrating Positivist and Interpretive Approaches to Organizational Research," Organization Science (2:4), 1991, pp. 342-365.

MacKenzie, D. Inventing Accuracy: A Historical Sociology of Nuclear Missile Guidance, Cambridge, MA: The MIT Press, 1993. 
Mathiassen, L. "Collaborative Practice Research," in Organizational and Social Perspectives on Information Technology, R. Baskerville, J. Stage, and J. I. DeGross (eds.), Boston: Kluwer Academic Publishers, 2000, pp. 127-148.

Mitev, N. N. "The Globalization of Transport? Computerized Reservation Systems at American Airlines and French Railways," in Promotheus Wired: History, Globalization and Technology, P. Lyth and H. Trischler (eds.), Cambridge, MA: The MIT Press, 2000.

Myers, G. The Art of Software Testing, New York: Wiley, 1979.

Pouloudi, N., and Whitley, E. A. "Representing Human and Non-human Stakeholders: On Speaking with Authority," in Organizational and Social Perspectives on Information Technology, R. Baskerville, J. Stage, and J. I. DeGross (eds.), Boston: Kluwer Academic Publishers, 2000, pp. 339-354.

Robey, D. "Research Commentary: Diversity in Information Systems Research: Threat, Promise, and Responsibility," Information Systems Research (7:4), 1996, pp. 400-408.

Sawyer, S. "Studying Organizational Computing Infrastructures: Multi-method Approaches," in Organizational and Social Perspectives on Information Technology, R. Baskerville, J. Stage, and J. I. DeGross (eds.), Boston: Kluwer Academic Publishers, 2000, pp. 213-232.

Schultze, U. "A Confessional Account of an Ethnography About Knowledge Work," MIS Quarterly (24:1), 2000, pp. 1-39.

Scott, S. "Lived Methodology: A Situated Discussion of 'Truth and Method' in Interpretive Information Systems Research," Information Systems Department Working Paper, London School of Economics 2000a (available at http://is.lse.ac.uk/wp/pdf/wp91.pdf).

Scott, S. "IT-Enabled Credit Risk Modernization: A Revolution Under the Cloak of Normality," Accounting, Management and Information Technologies (10:3), 2000b, pp. 221-255.

Scott, S., and Walsham, G. "Shifting Boundaries and New Technologies: A Case Study in the UK Banking Sector," in Proceedings of the Nineteenth International Conference on Information Systems, R. Hirschheim, M. Newman, and J. I. DeGross (eds.), Helsinki, Finland, 1998.

Sieber, S. "Enhancing Organizational Learning: An Ethnographic Study of Individual and Collective Learning Activities and Support Systems in a Multinational Engineering Company," IESE, Universidad de Navarra, 2000.

Sørensen, C. "Interaction in Action: Learning from Studying the Use of Technology," in Informatics in the Next Millennium, F. Ljungberg (ed.), Lund, Sweden: Studentliteratur, 1999, pp. 117-135.

Stengers, I. Power and Invention: Situating Science, Minneapolis: University of Minnesota Press, 1997.

Suchman, L. A. Plans and Situated Actions: The Problem of Human-Machine Communication, Cambridge, UK: Cambridge University Press, 1987.

Trauth, E. M., and Jessup, L. "Understanding Computer-Mediated Discussions: Positivist and Interpretive Analyses of Group Support System Use," MIS Quarterly (24:1), 2000, pp. 43-79.

Walsham, G. Interpreting Information Systems in Organizations, Chichester, UK: John Wiley \& Sons, 1993.

Walsham, G. "Interpretive Case Studies in IS Research: Nature and Method," European Journal of Information Systems (4:2), 1995, pp. 74-81.

Whitley, E. A. "Understanding Participation in Entrepreneurial Organizations: Some Hermeneutic Readings," Journal of Information Technology (14:2), 1999, pp. 193-202. 


\section{About the Authors}

Carsten Sørensen lectures Information Systems at London School of Economics and Political Science, United Kingdom (is.lse.ac.uk/staff/sorensen). He holds a B.Sc. (Math), an M.Sc. (Computer Science) and a Ph.D. (Computer Science and Information Systems) from Aalborg University, Denmark. Carsten's area of research is information and communication technology supporting complex work in technical domains. He has worked extensively in European research projects and conducted researched within, for example, software engineering, computer supported collaborative work, web navigation, the management of knowledge, and Internet technologies. Currently he is researching the management of interaction in knowledge intensive firms. Carsten is one of the founding members of the Internet Project (internet.informatik.gu.se). He is director of the action research project Laboratorium (laboratorium.htu.se) at Trollhättan Uddevalla University, Sweden. Carsten has through the past 12 years been affiliated with a number of Danish, Swedish and British institutions. He is a member of the IEEE Computer Society, Association for Computing Machinery, and the IRIS Association (iris.informatik.gu.se). He can be reached by e-mail at c.sorensen@lse.ac.uk.

Edgar Whitley is a senior lecturer in Information Systems at the London School of Economics and Political Science. He has a B.Sc. (Economics) Computing and a Ph.D. in Information Systems, both from the LSE. He has taught undergraduate and postgraduate students as well as managers in the UK and abroad. Edgar was one of the organizers of the First European Conference on Information Systems and is actively involved in the coordination of future ECIS conferences. He has published widely on various information systems issues and is currently editing a special issue of The Information Society on "Time and Information Technology." He is one of the program chairs for the forthcoming IFIP 8.2 conference on organizational discourse and information technology to be held in Barcelona in December 2002. Edgar can be reached by e-mail at e.a.whitley@lse.ac.uk.

Shirin Madon is a lecturer in Information Systems at the London School of Economics and Political Science, United Kingdom. She has a B.A. (Economics) and an M.Sc. (Information Technology) from Kingston University, UK, and a Ph.D. (Information Systems) from Imperial College, London. Shirin's main research interest is information systems for public sector planning and administration in developing countries. She has done extensive fieldwork in India as part of her doctoral studies and later on funded research programs. This fieldwork has involved longitudinal research over many years in order to trace the interplay between technological and social factors in complex rural and urban settings in India. Shirin can be reached by e-mail at s.madon@lse.ac.uk. 
Dasha Klyachko is a Ph.D. student in the Department of Information Systems at the London School of Economics and Political Science (United Kingdom). Her research is concerned with new organizational forms that arise as a result of outsourcing decisions. She holds an M.Sc. Degree in computer science and Applied Mathematics from Gubkin Institute, Moscow, and has previously worked as a software developer in the financial services industry. Dasha can be reached by e-mail at d.klyachko@lse.ac.uk.

Ian (Gus) Hosein is a doctoral student in Information Systems at the London School of Economics and Political Science. Since 1997, he has lectured to undergraduate and postgraduate students on topics including a history of computing, networks, computer security, the Information Society concept, and the political and regulatory interests in technology. He has also presented at institutions including Cambridge University, Johns Hopkins, and the University of Witwatersrand. His area of research is technology policy, with a core concentration on national and international initiatives, focusing on secure communication techniques. Through his work with Privacy International, the Foundation for Information Policy Research, and Zero-Knowledge Systems, he has also spoken at OECD, UNESCO, and Royal Institute for International Affairs sponsored events, and participated at G8 and Data Protection Commissioners conferences. He is a survivor of a B.Math Hons. Applied Mathematics (University of Waterloo), and an M.Sc. (LSE). More information is available at http://is.lse.ac.uk/staff/hosein. Gus can be reached by e-mail at i.hosein@lse.ac.uk.

Justine Johnstone is a Ph.D. student in the Department of Information Systems at the London School of Economics and Political Science (United Kingdom). Her research is concerned with the use of ICTs in supporting knowledge-based development in poor countries. She holds a B.A.Hons. from the University of Natal (South Africa) and an M.A. from the University of London (United Kingdom) in Philosophy. Justine can be reached by e-mail at j.e.johnstone@1se.ac.uk. 